قياس تركيز المنظفات (سلقونات البنزين الالكيلية المستقيمة) الملوثة لمياه نهر دجلة في مدينة الموصل ومعالجتها بالكاريون المنشط الحبيبي (المكبرت والمفسفر)

د. أروى محمد عثمان د د. هدى عبد الرزلق البكري مدرس - م
مدرس - ماس

المعهز التقني في الموصل قسم الصناعات الكيمياوية

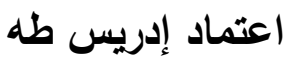

المعهز التقني في الموصل قسم الصناعات الكيمياوية \section{مدرس}

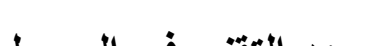
المعهد التقني في الموصل قسم الصناعات الكيمياوية

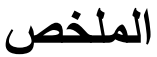

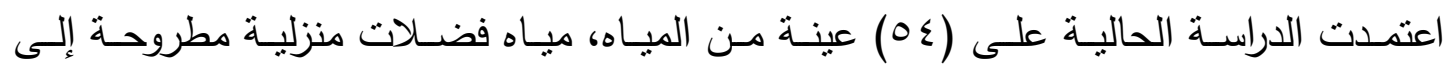

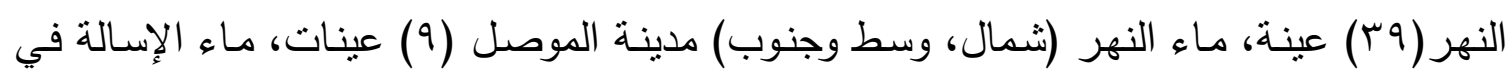

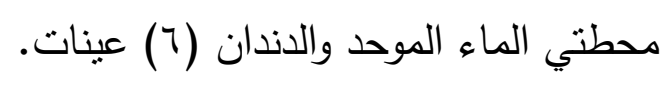

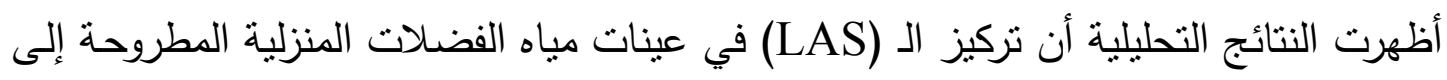

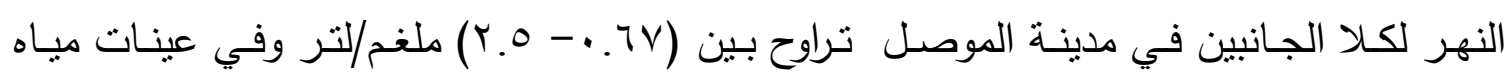

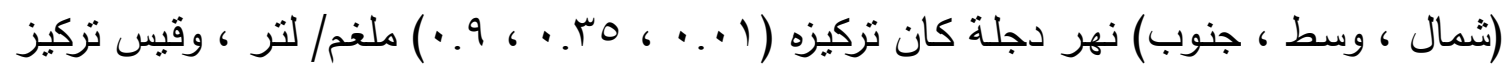

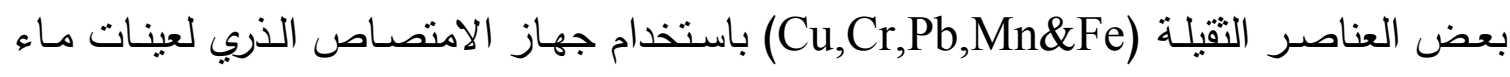
النهر الخام وماء الإسالة لمحطتي (المـاء الموحد والدندان) ، وتم احتساب النسبة المئويـة لإزالـة العناصر التقبلة (Cu,Cr,Pb,Mn\&Fe) في محطتي التصفية.

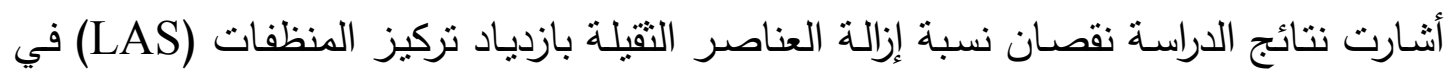
مياه النهر وهذا يؤكد أن (LAS) تعمل كعامل انتشار (Dispersion) للعناصر الثقيلة في المياه الملوثة مما يعيق ترسبها وإزالتها. ولغرض تخفيف المخاطر البيئية والصحية للتلوث بالمنظفات تم معالجة عينات المياه الملوثنة

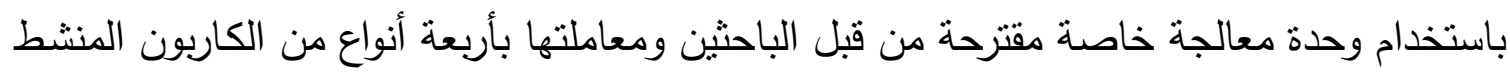

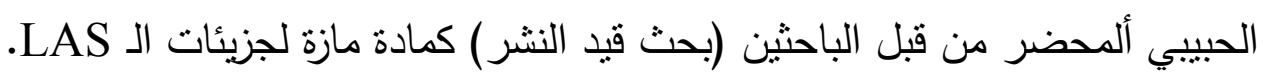

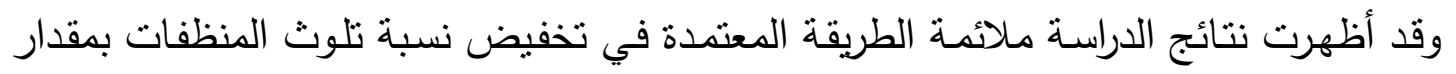

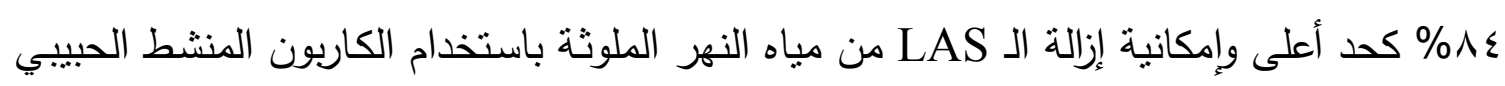

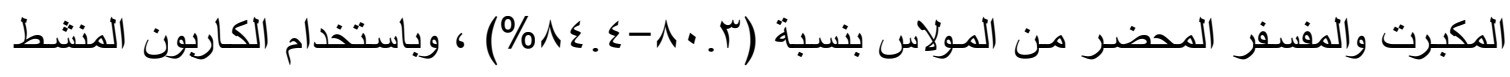




$$
\begin{aligned}
& \text { الحبيبي المكبرت والمفسفر المضر من الإسفلت بنسبة (•؟-97\%) عند ظروف مختبرية خاصة }
\end{aligned}
$$

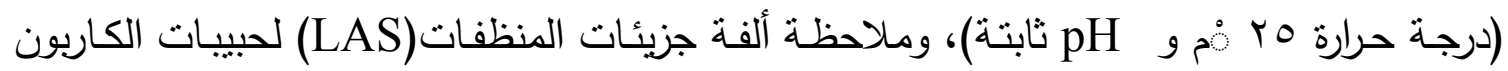

$$
\begin{aligned}
& \text { المنشط المكبرت أكثر من حبيبات الكاربون المنشط المفسفر . }
\end{aligned}
$$

\title{
Measurements of Detergents Concentration (Linear Alkyl Benzene Sulfonates LAS) for Tigris River Water in Mosul City and Treatment with Sulphurized and Phosphorized Granular Activated Carbon
}

\author{
I'temad A. Taha \\ Lecturer \\ Mosul Technical Institute \\ Chemical Industries Dep.
}

\author{
Dr. Arwa M. Othman \\ Lecturer \\ Mosul Technical Institute \\ Chemical Industries Dep.
}

\author{
Dr. Huda A. AlBakry \\ Lecturer \\ Mosul Technical Institute \\ Chemical Industries Dep.
}

\begin{abstract}
The present study depended on (54) samples of water, nunicipal wastewater (39) samples Tigris river water (north, middle and south) of Mosul city (9) samples and water supply treatment plants (Al-Maa AlMuwahad \& Al-Danadan) (6) samples.

Analytical results showed the LAS concentration in nunicipal wastewater samples may vary between $(0.67-2.5) \mathrm{mg} / \mathrm{L}$ and in Tigris river water (north, middle and south) was found $(0.01,0.35 \& 0.9) \mathrm{mg} / \mathrm{L}$ respectively. The concentration of some heavy metals $(\mathrm{Cu}, \mathrm{Cr}, \mathrm{Pb}, \mathrm{Mn} \& \mathrm{Fe})$ was measured using atomic absorption spectrophotometer for the river raw water samples and water supply treatment plants samples. The removal affinity percentage of heavy metals $(\mathrm{Cu}, \mathrm{Cr}, \mathrm{Pb}, \mathrm{Mn} \& \mathrm{Fe})$ was calculated.

Study's results indicated decreasing in heavy metals removal efficiency with increasing in detergents (LAS) concentration in Tigris river water, this improved (LAS) acts as a dispersion factor for heavy metals in wastewater which prevents its sedimentation and removing.

In order to decrease the environmental and health dangers of detergents pollution, wastewater curing by using a special unit of treatment (suggested by the investigators) with four types of granular activated carbon (GAC)
\end{abstract}


which prepared by investigators (research under edditing) as adsorbent for LAS molecules.

Study's results show the dependent method suitibility in reducing detergents pollution percentage by $84 \%$ as a maximum. The ability of LAS uptake from river wastewater by using sulfurized and phosphorized GAC obtained from Molasses was found to be (80.3-84.4\%), by using sulfurized and phosphorized GAC obtained from asphalt was found to be (30-69\%) at special laboratory condition (temperature $25^{\circ} \mathrm{c}$ and constant $\mathrm{pH}$ ), that showed a high affinity of LAS molecules toward sulfurized GAC more than phosphorized GAC.

\section{المقدمة}

لقد ترتب على التوسع الصناعي وخاصـة بعد الحرب العالمية الثنانية استخدام المنظفات بكثرة

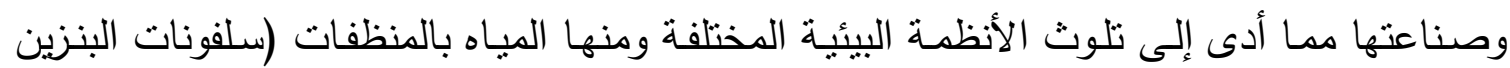

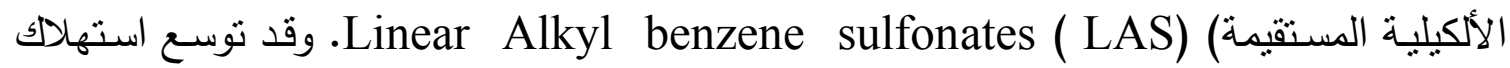
المنظفات في الدول الناميـة نتيجة النطور الحضـاري وظهور أنواع مختلفة من المنظفات، وتؤثنر المنظفات بشكل مباشر وغير مباشر على الموارد المائية وذلك لاحتوائها على مواد كيمياوية ضارة وتتكل مادة صوديوم ثلاثي_متعدد الفوسفات Sodium-Tripolyphosphate الذائبة في الماء جزءً كبيراً منها وتدخل هذه المـادة (مركب الفوسفات) مـع مطروحات الفضـاتلات المنزلية بالدرجـة

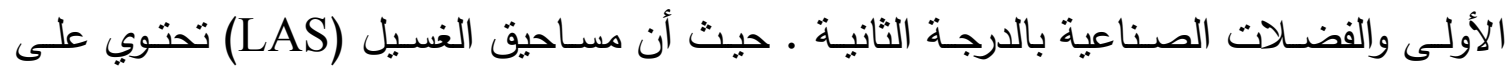
مركبات كيمياوية لها تأثيرها الفعلي في التتظيف وتتضمن سلفونات البنزين الالكيلية وثلاثي فوسفات الصوديوم

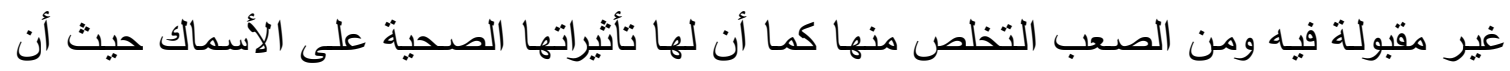

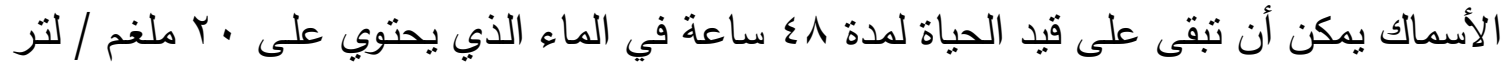

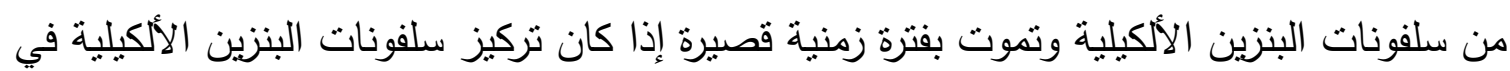

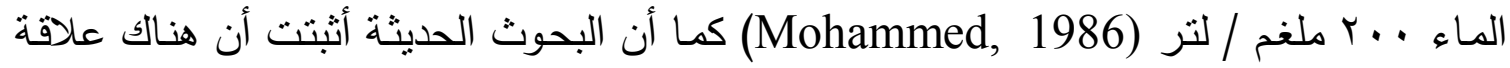
واضحة بين وجود المنظفات في الماء وبين أمراض تلف الكبد بالإضـافة إلى أن وجود مركبات

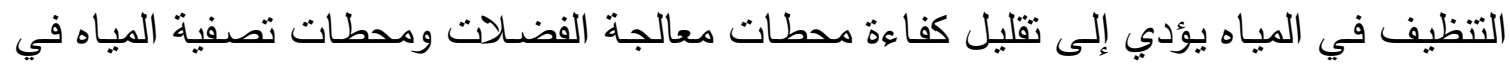
إزالة الكثير من الملوثات الخطيرة كالعناصر الفلزيـة (Fe,Mn,Pb,Cr,Cu) حيث إنها تزيد من

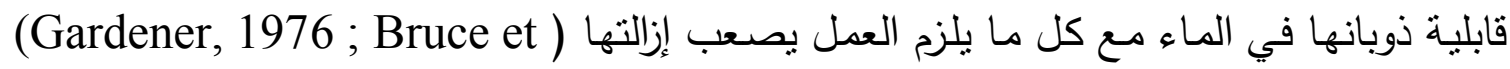


ونظراً لأهمية هذا الموضوع فقد نم دراسة المشكلة باستخدام الفحم المنشط كمادة مازة لتتقية المياه الملوثة وتعتبر هذه الطريقة هي الطريقة المنلى والاقتصادية لإزالة منل هذه الملوثات (Jim, 2002)

يعد الكاربون المنشط أحد صور الكاربون غير البلوري وهو مادة كاربونية مسامية التركيب تلعب

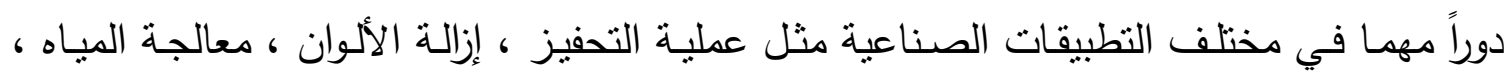
السيطرة على التلوث ، فضلاً عن العديد من الاستخدامات الأخرى (Saleem, 1978) و (

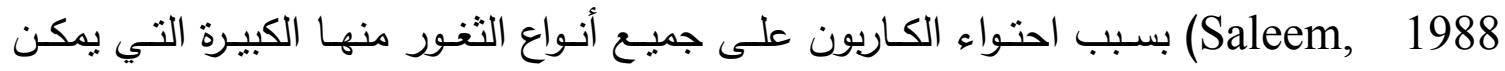

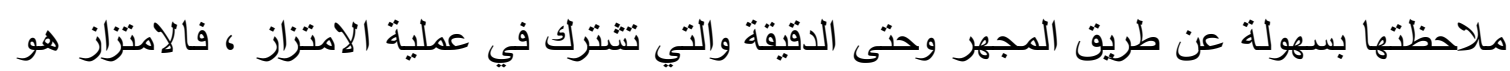

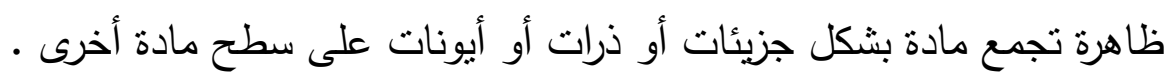

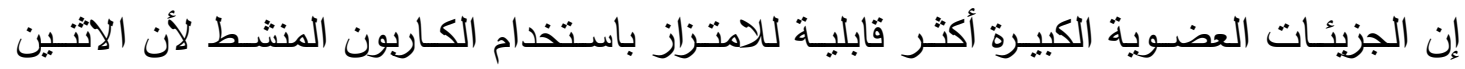

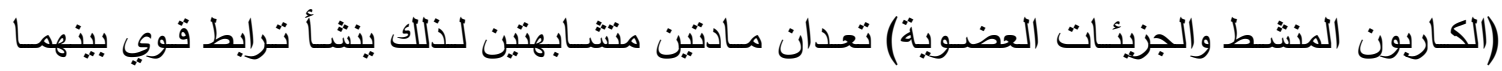

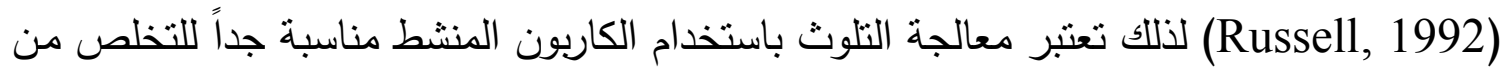

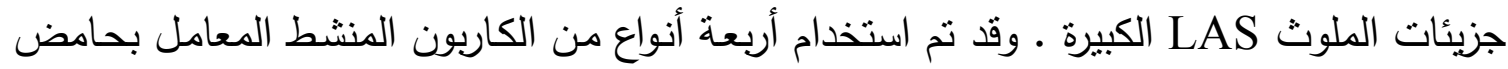
الكبريتيك وبحامض الفسفريك المركزين والمحضر من مادتي المولاس والإسفلت (Saad, 2003 ) لإزالة مركبات مساحيق التنظيف الملوِثة لمياه النهر والتي تبين بأن لها قابلية عالية على امتزاز مثل هذه الجزيئات من خلال النتائج التي تم الحصول عليها من خلال تعيين فعالية الكاربون المنشط قبل

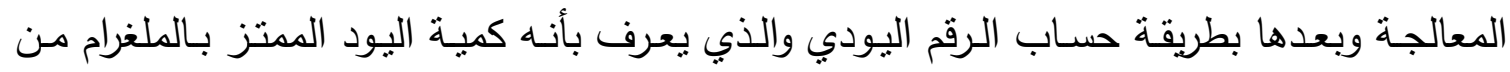

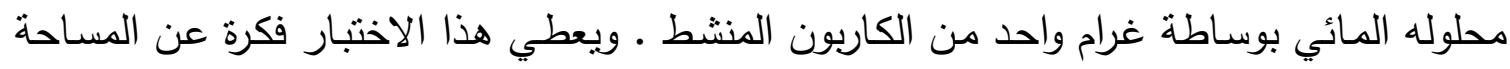
السطحية للكاربون المنشط (عماد ، 1997). يهدف البحث إلى قياس تركيز المنظفات ومعالجتها باستخدام الفحم المنشط وخاصة سلفونات

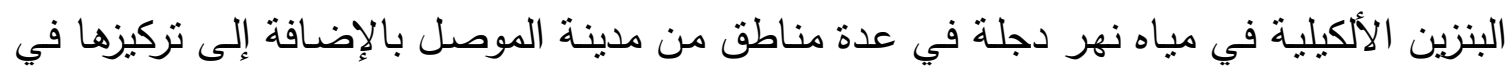

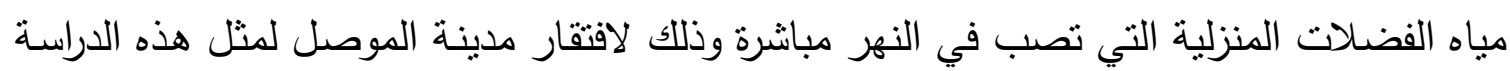

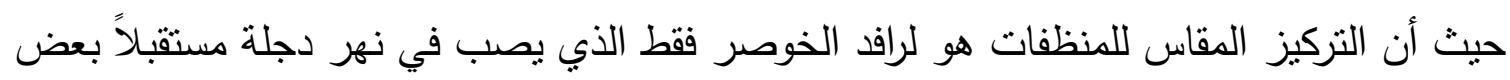

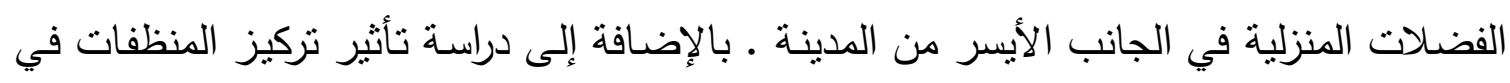

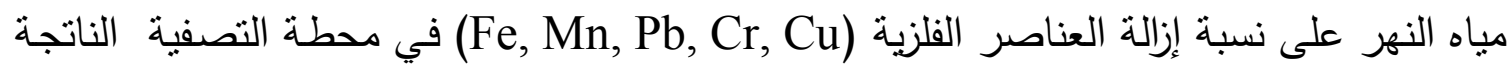
من فضلات معامل الصباغة والدباغة وغسل السيارات وخاصة الرصاص من بنزين السيارات حيث يحوي على رابع اثيلات ورابع مثيلات الرصاص كمواد إضاعله وعنية. 


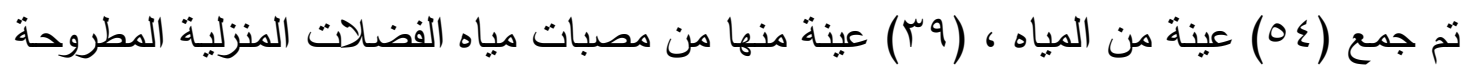

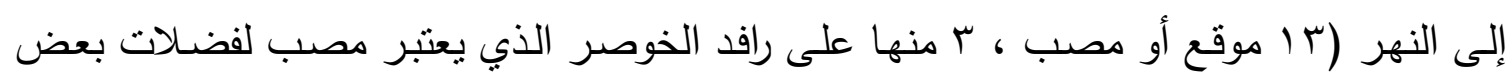

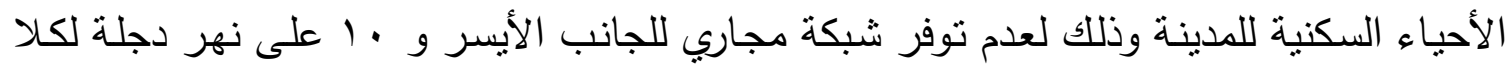

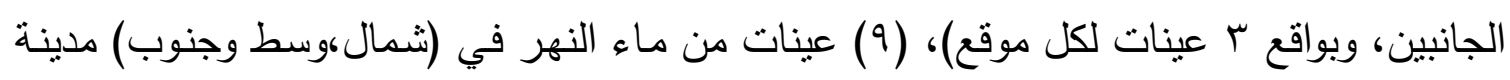
الموصل. شمال مدينة الموصل قرب محطة تصفية الماء الموحد وعينات أخرى من جنوب المدينة

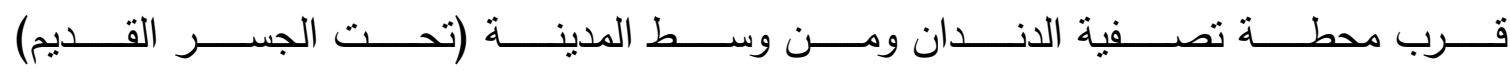
شكل (1). أما بالنسبة لمعرفة تأثير نركيز المنظفات في إزالة العناصر الفلزية الثقيلة في محطات

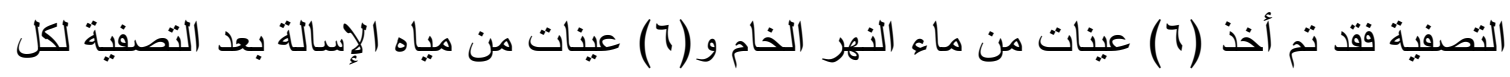

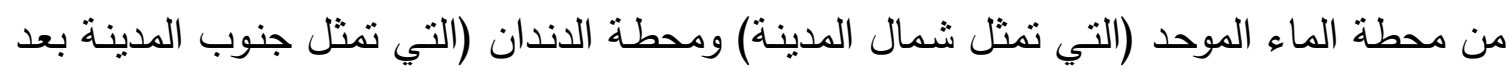
طرح الفضلات المنزلية إلى النهر) . كما نم اخذ العينات الدذكورة جميعا على شكل عينات عشوائية منفردة على أعماق مختلفة.

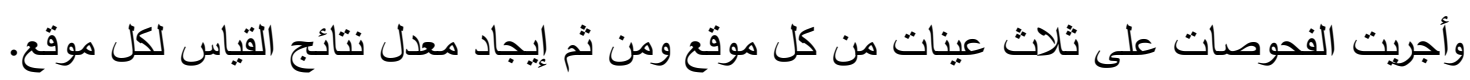

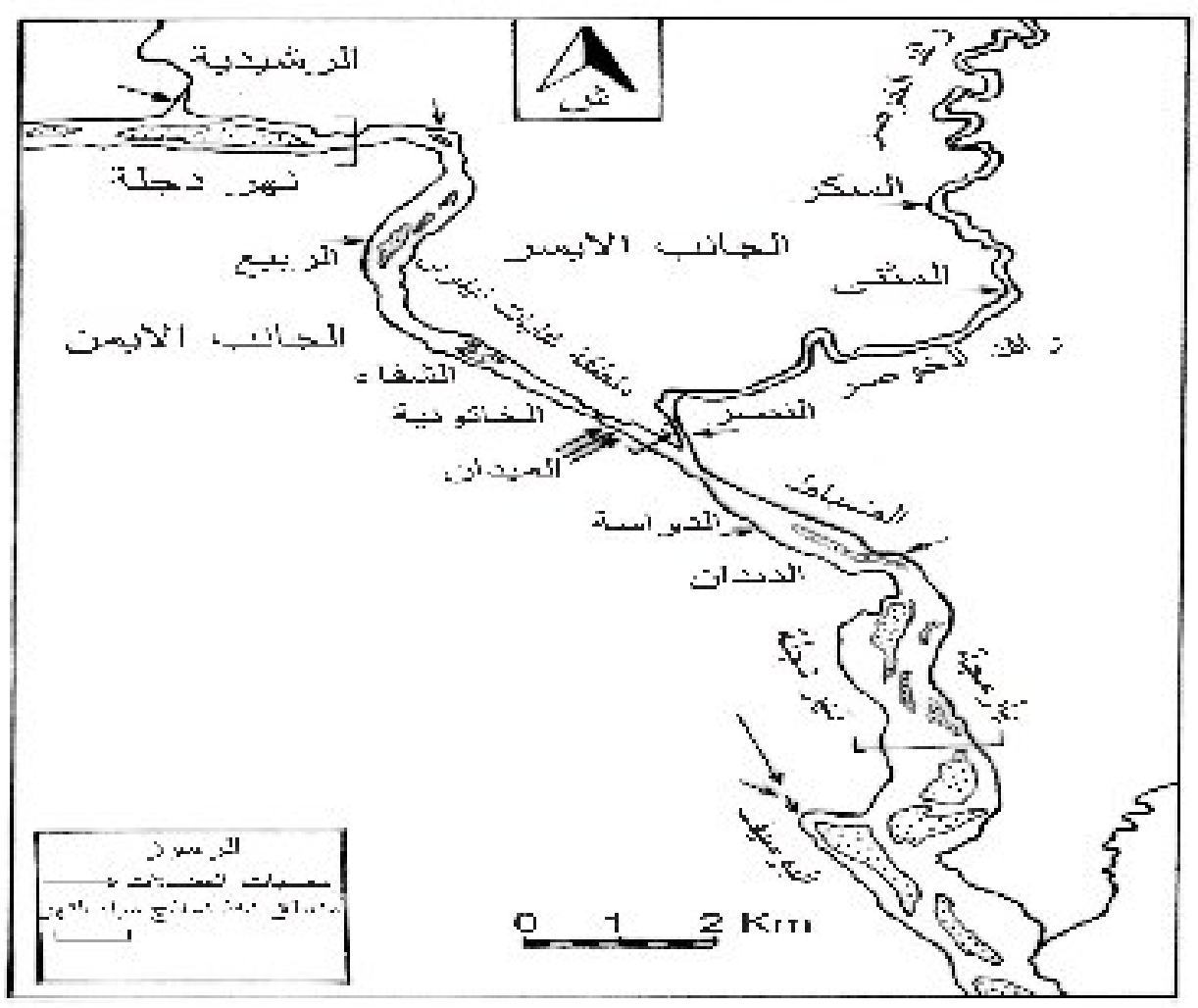

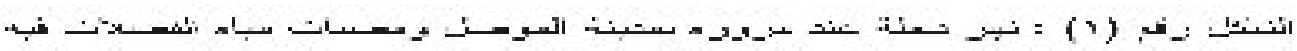


1. تعيين سلفونات البنزين الأكيلية (LAS)

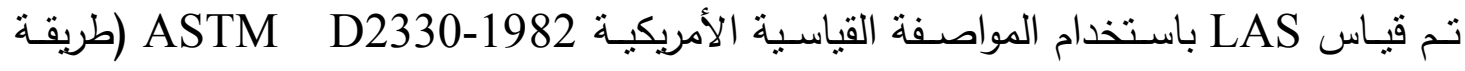

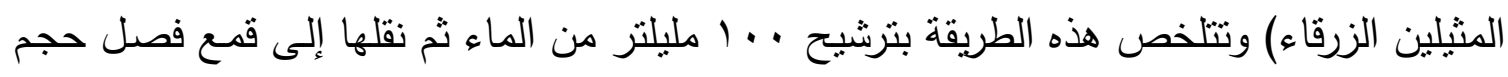

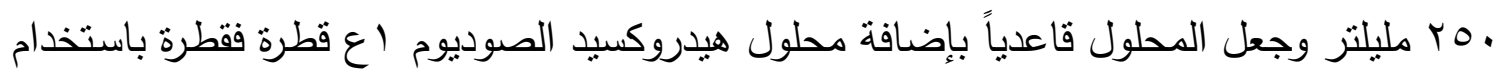
الفينونفتالين كدليل، فعند ظهور اللون الوردي يضاف محلول حامض الكبريتيك الع إلى ألى أن يختفي

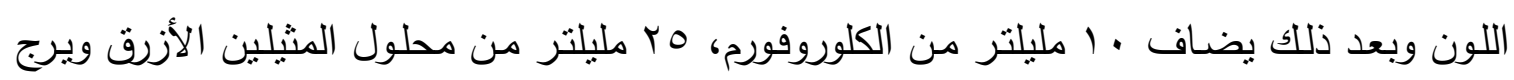

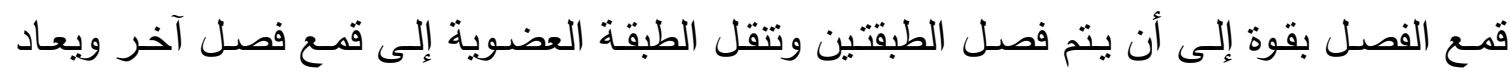

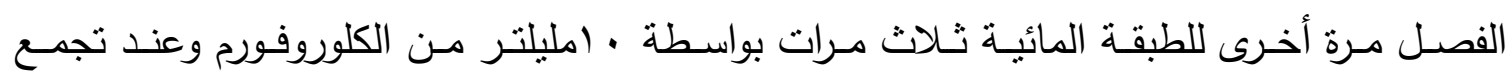

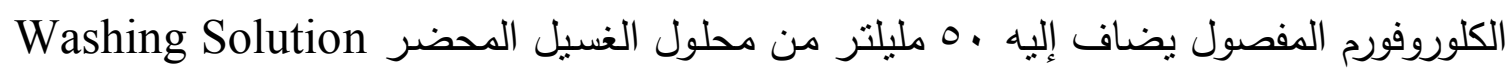

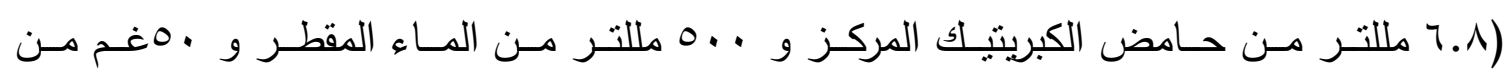

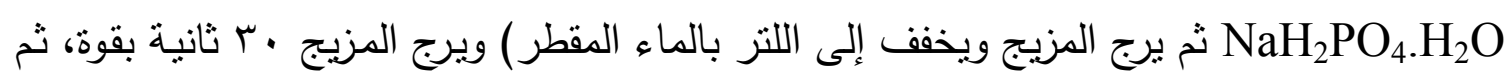
تفصل طبقة الكلوروفورم، ويعاد الفصل مرة أخرى بإضافة ـ ـ مليلتر من الكلوروفورم إلى الطبقة المائية ، ثم يجمع الكلوروفورم في قنينة حجم •0 ملبلتر بعد ترشيحه ويكمل الحجم إلى حد الإثـارة.

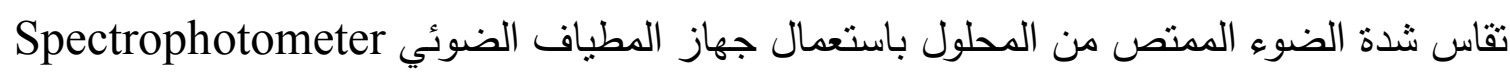

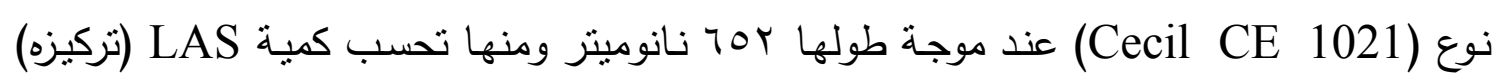

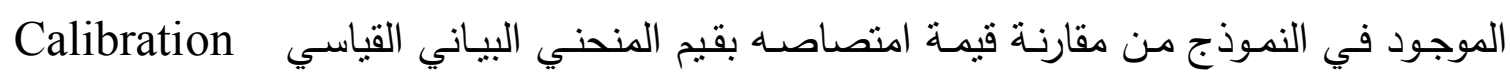

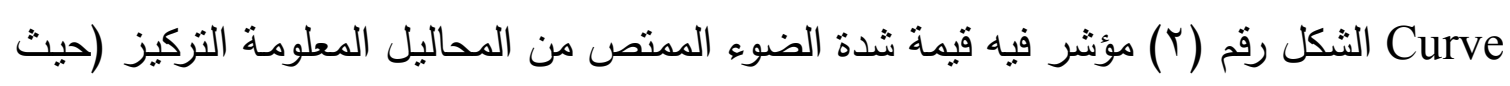

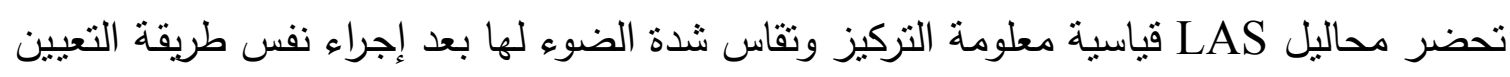

المذكورة آنفا) ( سعاد و محمد، . 99 (1) ) .

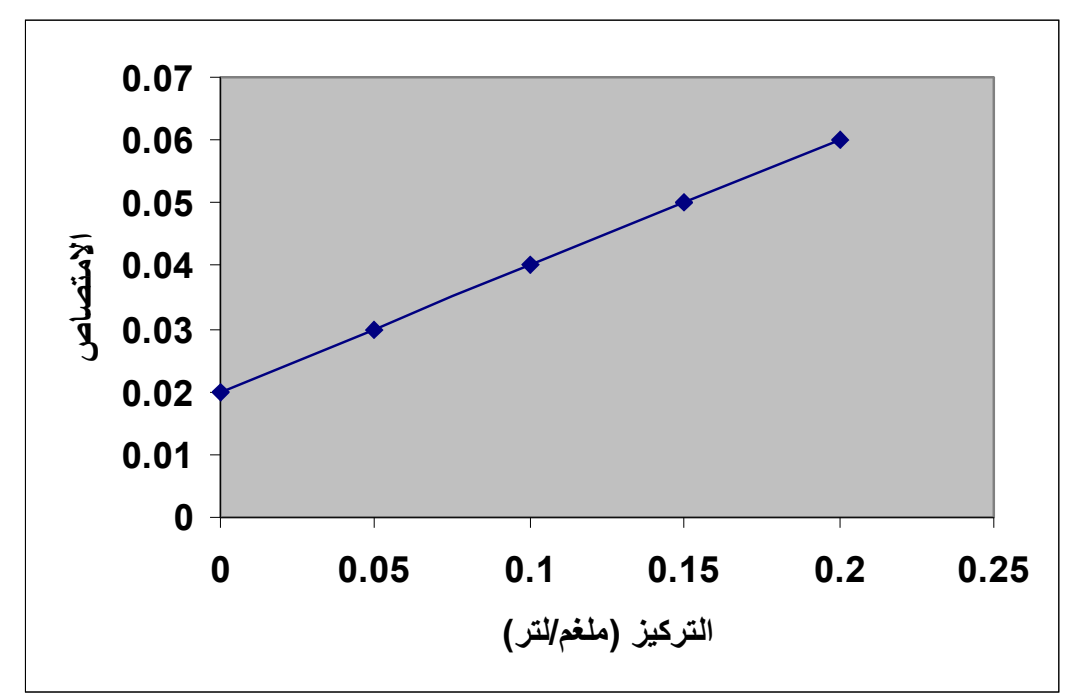

LAS الثكل رقم (ץ) : المنحني البياني القياسي لمحاليل 


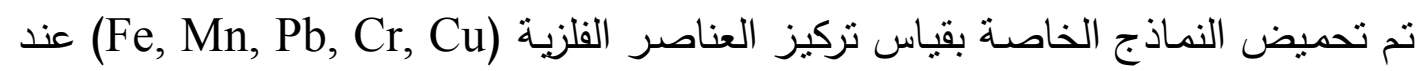
أخذها لكلا الماء الخام والماء بعد التصفية لكلا المحطنين وذلك لإبقائها في الماء ومنع امتزازها

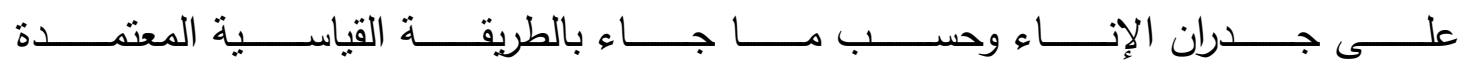
، (standard Method for Examination of water and wastewater ,1975)

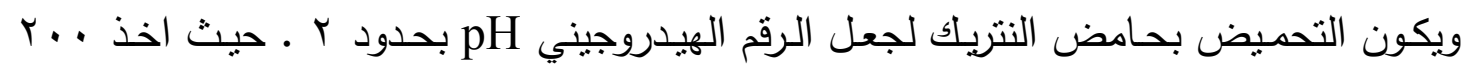

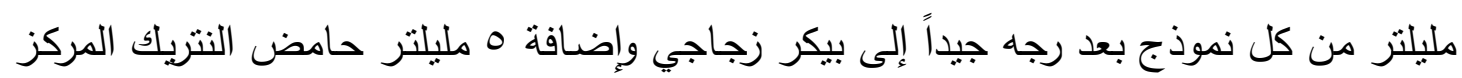

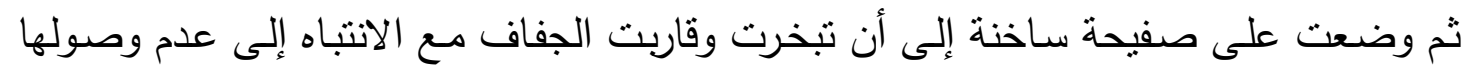

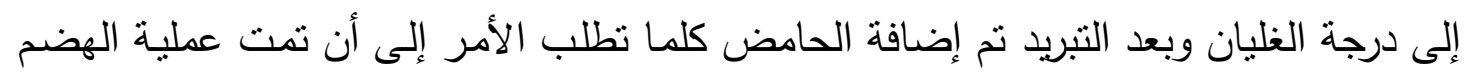

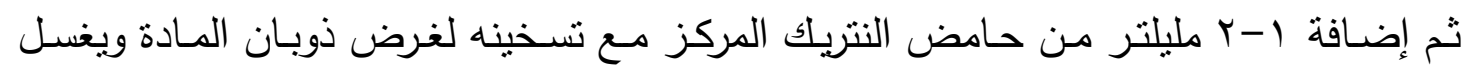

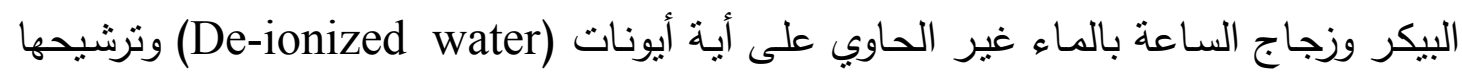

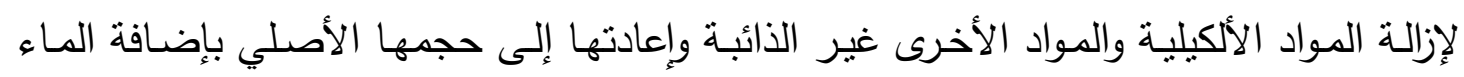

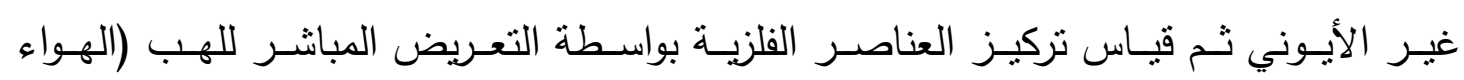

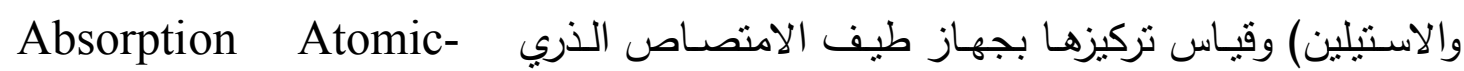

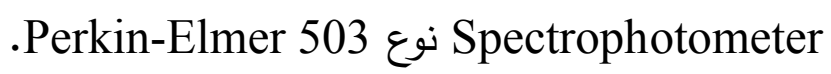
r. معالجة سلفونات البنزين الأكيلية LAS باستخدام الكاريون المنشط الحبيبي :

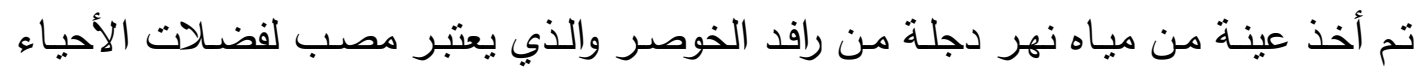

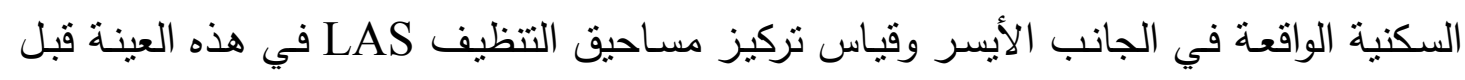

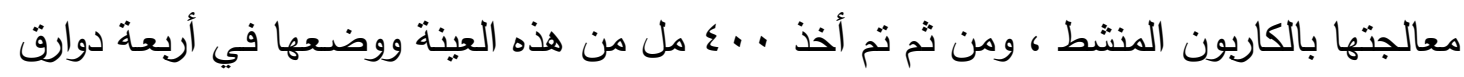

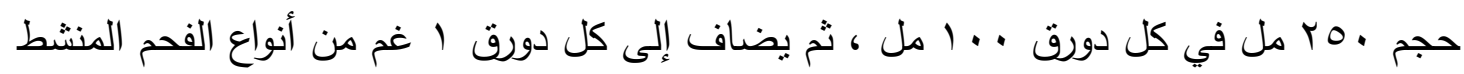

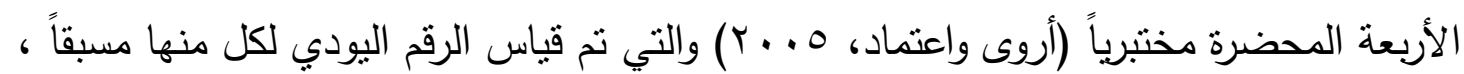

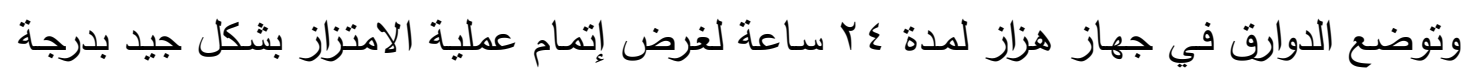

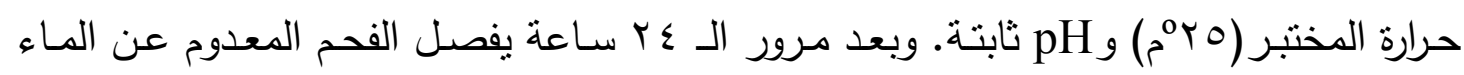
المعالج وبعدها ينتم قيـاس نركيز الملوث LAS فيـه ، ويقاس الرقم اليودي للفحم المعدوم. والثكل رقم(ץ) يبين تصميم لوحدة معالجة بعملية الامتزاز باستخدام الكاربون الحبيبي المنشط. 


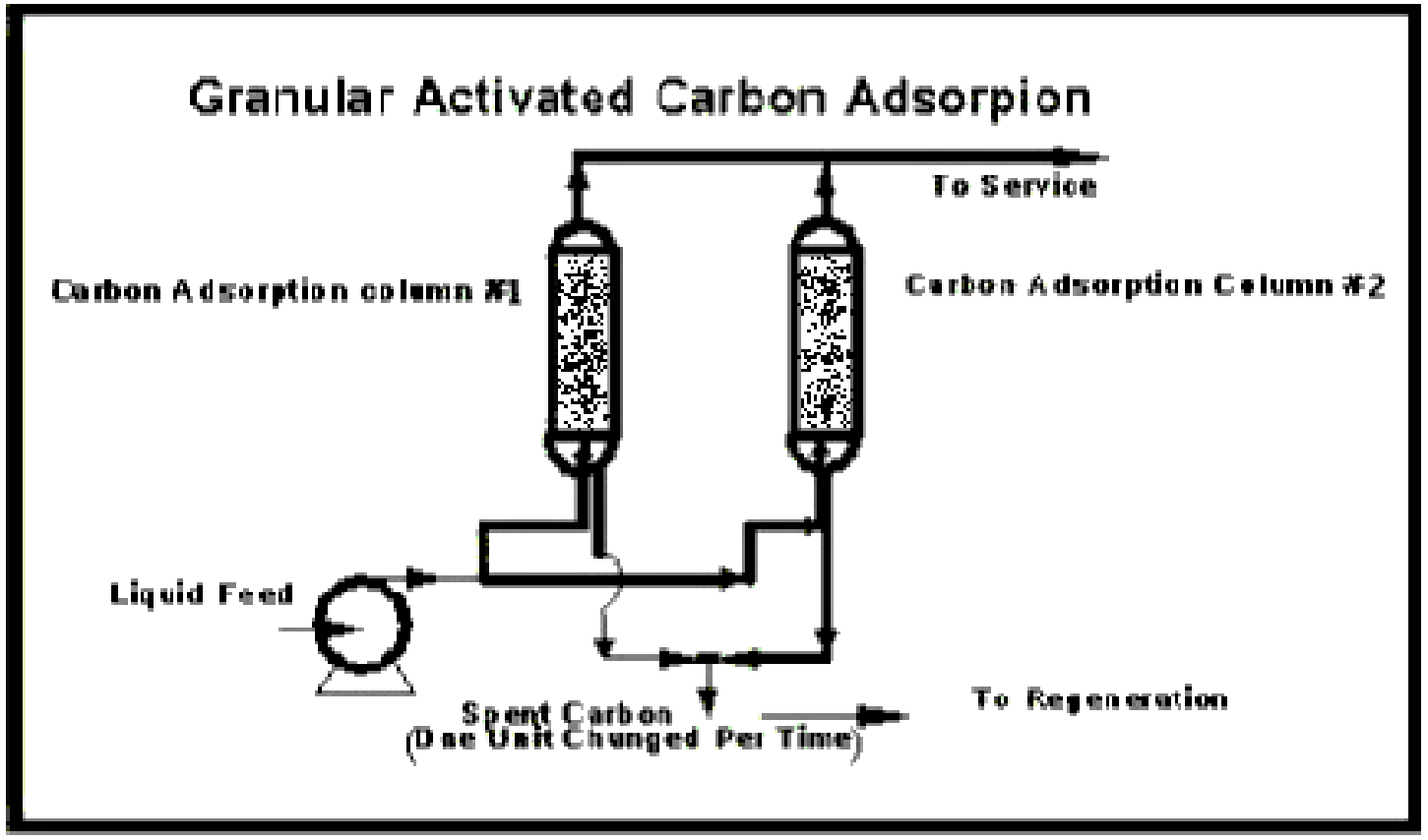

الشكل رقم(ب) : وحدة معالجة الماء الملوث بالامتزاز بالكاريون الحبيبي المنشط

ع ـ تعيين فعالية نماذج الكاريون المنشط المحضر بطريقة قياس الرقم اليودي لكل منهم قبل ويعد المعالجة :

تم قياس الرقم اليودي للكاربون المنشط المستخدم قبـل وبعد المعالجـة باستخدام المواصفة القياسية الأمريكية 1994-ASTM D4607 وتتلخص الطريقة بالخطوات التالية: ا ـ نضع غرام واحد من الكاربون المنشط في دورق جاف سعته . . r مل . r. ينقل بوساطة ماصة • (1 مل من محلول 0\% حامض الهيدروكلوريك إلى الدورق •

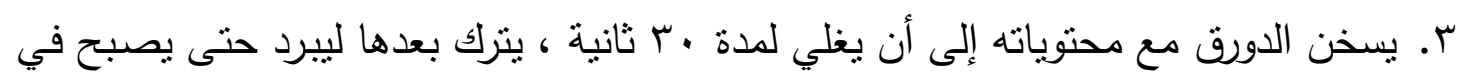
درجة حرارة المختبر ع. يضاف إلى الدورق · . . مل من محلول اليود (0.1 N) . ه. يوضـع الدورق في جهاز الرج الكهربائي لمدة نصف ساعة وبعد ذلك يتم ترشيح محتويات الدورق بوساطة ورقة ترشيح جافة ونظيفة ويهمل حوالي · r مل من الراشتح في بداية عملية الترشيح ويجمع الباقي في دورق نظيف .

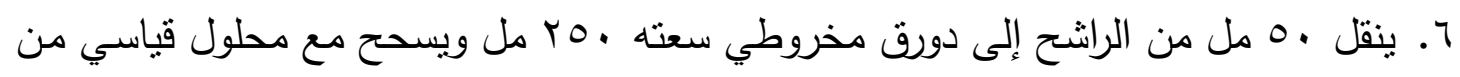

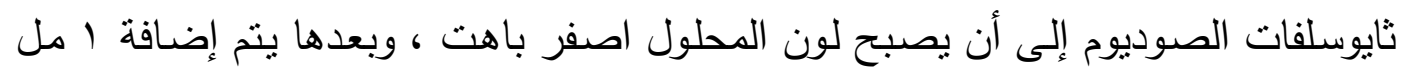
مـن دليـل النشـا ويكمل التسـيح إلىى أن يختفي اللـون الأزرق ويحسب حجم الثايوسـلفات 
V. يتم حساب وزن اليود الممتز من قبل نماذج الكاربون المنشط بنطبيق المعادلة $\mathrm{X}=\mathrm{A}-[2.2 \mathrm{~B} \times \mathrm{ml}$ of Thiosulfate solution used].

$\mathrm{A}=\mathrm{N}_{1} \times 12693$

$\mathrm{B}=\mathrm{N}_{2} \times 126.93$

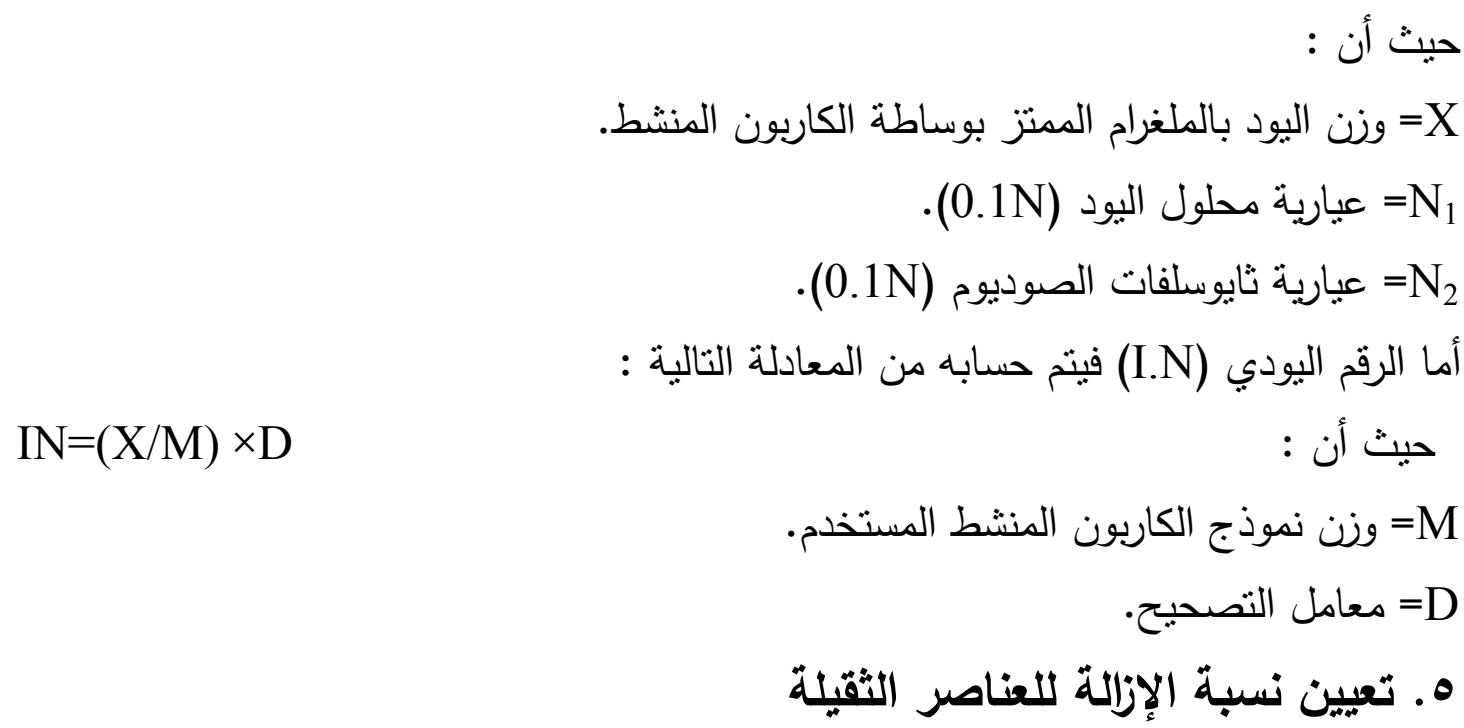

تم تعيين نسبة الإزالة للعناصر التقيلة في كل من الماء الخام أو الملوث والماء

النقي (ماء الإسالة) حسب القانون الآتي:

Removal affinity $\left(\mathrm{R}_{\mathrm{a}} \%\right)=\left[\left(\mathrm{C}_{\mathrm{r}}-\mathrm{C}_{\mathrm{p}}\right) / \mathrm{C}_{\mathrm{r}}\right] \times 100$

Ra

C تركيز العنصر التقيل في الماء الخام أو الملوث.

C : تركيز العنصر الثقيل في الماء النقي (ماء الإسالة).

النتائج والمناقشة :

L-ب تركيز LAS في مياه الفضلات :

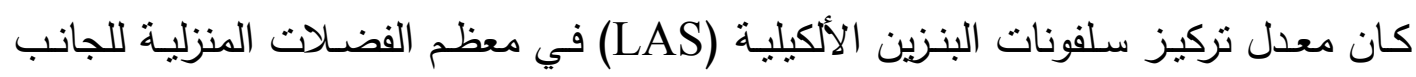

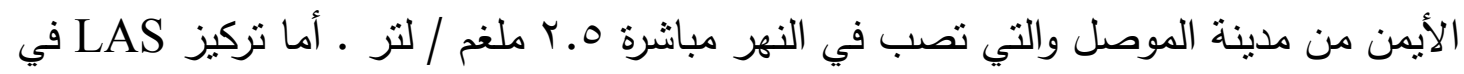

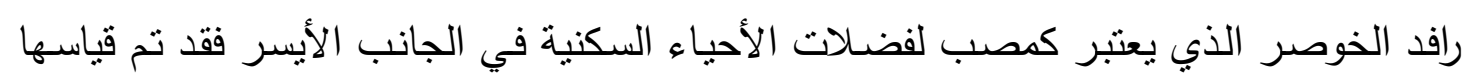

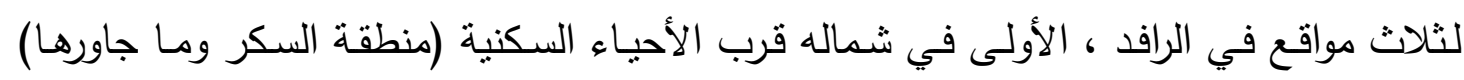

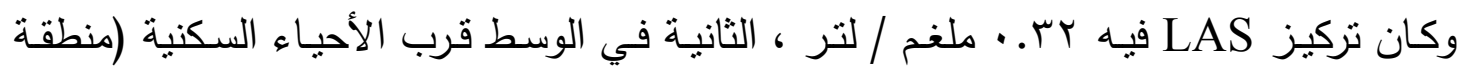

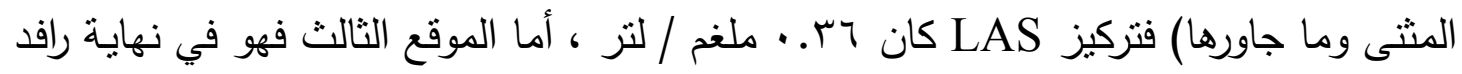


الخوصر وقرب مصبه إلى نهر دجلة فيمثل أعلى نركيز فقد كان ^هـ. ملغخ/لتر ، جدول (1)

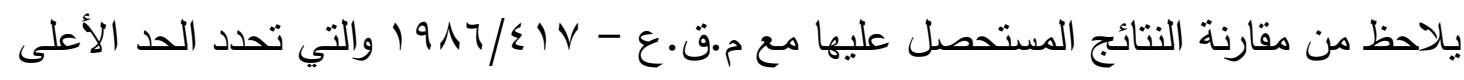

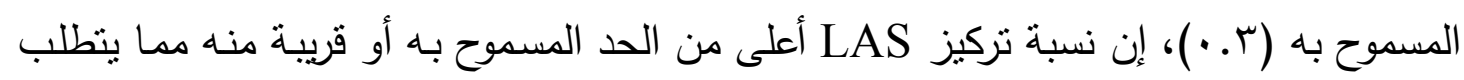

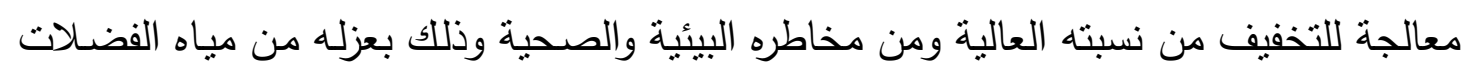
قبل إرسالها إلى النهر.

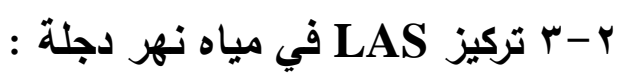

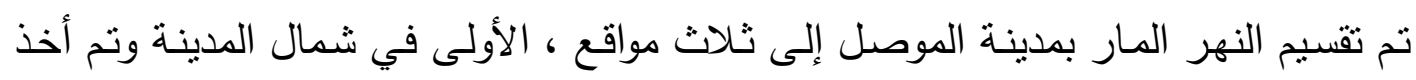

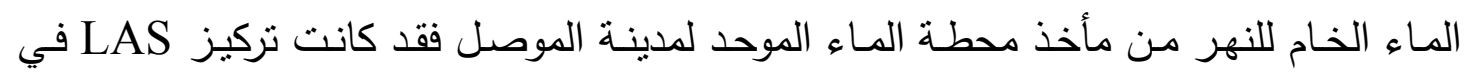

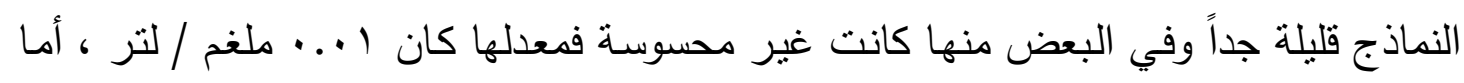

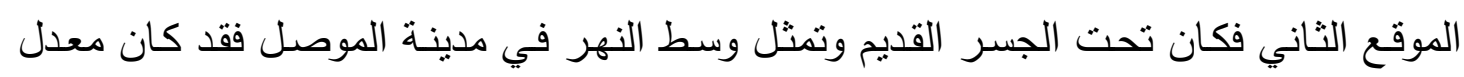

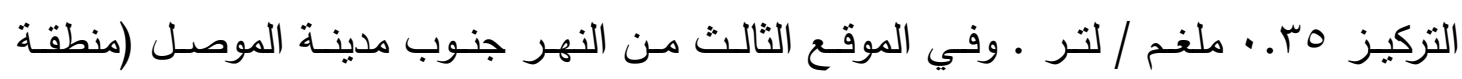

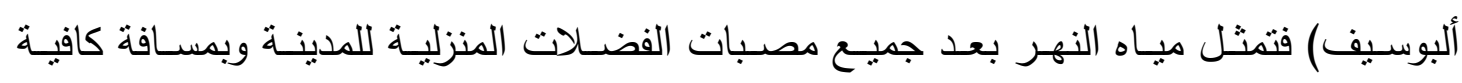

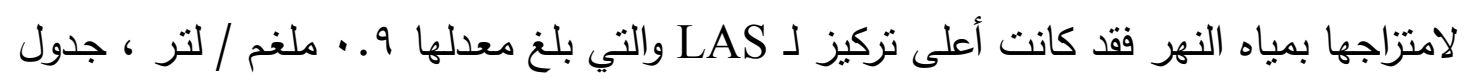

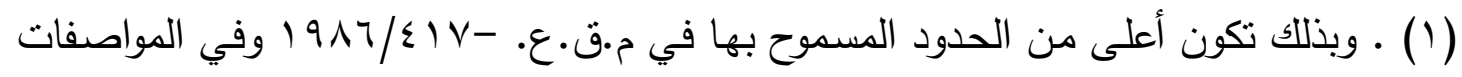

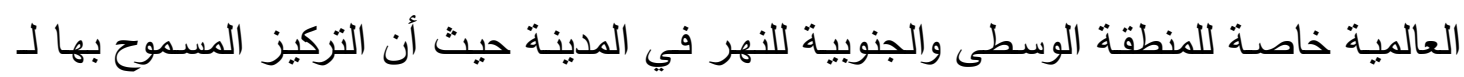

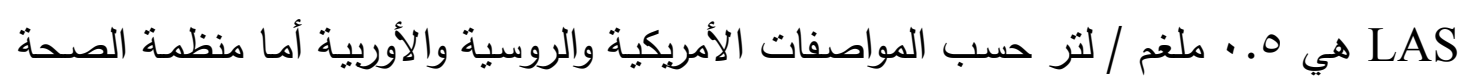
العالمية فقد حددت التركيز المسموح بها ب. . ملغم / لتر (Floyd ,1971;Carol,1977) من حيث تأثثرها السلبي على نوعية الماء.

جدول (1) : تركيز LAS في مياه الفضلات المنزلية ورافد الخوصر ونهر دجلة .

\begin{tabular}{|c|c|}
\hline تركيز LAS ملغم / لتر & النموذج \\
\hline$\cdot . r \pm r . \theta$ & معدل الفضلات المنزلية للجاتب الأيمن لمدينة الموصل \\
\hline$. . r \pm . . r r$ & معدل التركيز في رافد الخوصر (منطقة السكر) \\
\hline$\cdot . r \pm \cdot r r$ & منطقة المثىى \\
\hline$\cdot . r \pm 1 . r \Lambda$ & مصب الخوصر في نهر دجلة لمدينة الموصل \\
\hline $0.0 \pm \ldots 1$ & 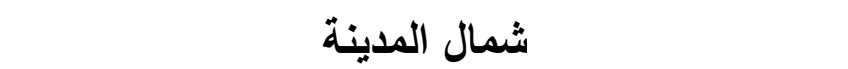 \\
\hline$\cdot . r \pm \cdot . r \Delta$ & وسط المدينة \\
\hline$\because . r \pm \ldots q$ & جنوب المدينة \\
\hline
\end{tabular}


r-r تأثير المنظفات على إزالة العناصر الفلزية في محطة التصفية

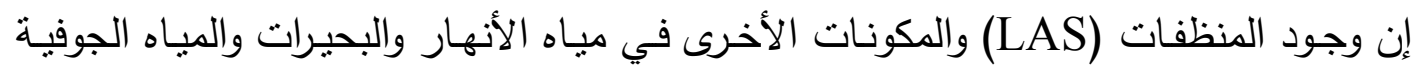

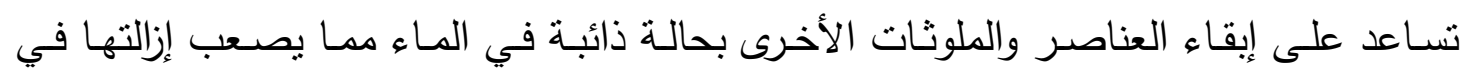

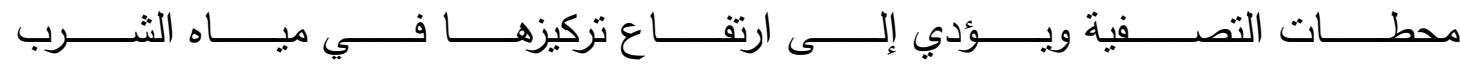
( Gardener, 1976 ; Bruce et al, 1969) الفلزية كالحديد والمنغنيز والرصاص والكروم والنحاس لتأثيراتها الصحية السلبية على الإنسان في محطات التصفية قيد الدراسة وتم مقارنة نسبة الازالة هذه ما بين محطة الماء الموحد التي يكون الإن تركيز المنظفات في الماء الخام لهذه المحطة قليلة جداً ومحطة الدندان الذي يحوي الماء الخام

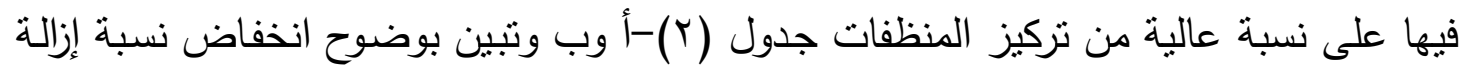
العناصر الفلزية قيد الدراسة في محطة الدندان بسبب وجود تركيز عالي للمنظفات في الماء الخام للنهر لتلك المنطقة ـ دلت النتائج بشكل واضح أن نسبة LAS لها تأثنرات سلبية فكلما

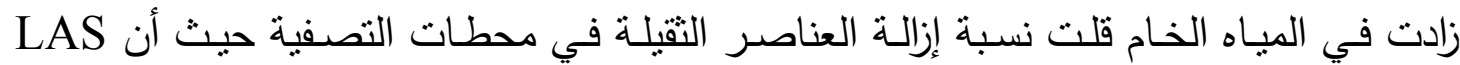
يلعب دور عامل انتشار للعناصر الثقيلة في المياه الملوثة مما يمنع ترسبها وإزالتها. وباستخدام

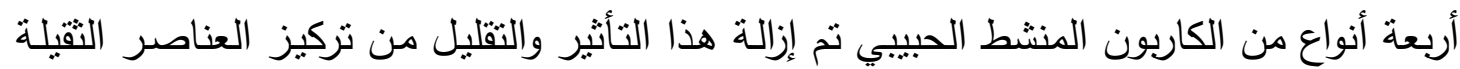
بامتزاز LAS من المياه الملوثة قبل طرحها إلى النهر •

جدول (r)-أ: تأثير LAS على التركيز الفعلي للعناصر المعدنية في محطة التصفية .

\begin{tabular}{|c|c|c|c|c|c|c|}
\hline \multicolumn{5}{|c|}{ تركيز العناصر مايكروغرام/تتر } & \multirow{2}{*}{\multicolumn{2}{|c|}{ محطة التصفية }} \\
\hline $\mathbf{C u}$ & $\mathrm{Cr}$ & $\mathbf{P b}$ & Mn & $\mathbf{F e}$ & & \\
\hline r. & r. & 10 & r. & $1 \ldots$ & في الماء الخام & محطة الماه المهدي \\
\hline 9.7 & 0.7 & V.० & 0 & 10 & في الماء النقي & الخام ا... ملغم / LAS في الماء \\
\hline Ir. & $1 \ldots$ & A. & o. & $10 \ldots$ & في الماء الخام & محطة الدندان. \\
\hline V५. & $\varepsilon r$ & Or & rV.o & $\vee \wedge$. & في الماء النقي & الخام 9. . ملغع / LAS في الماء \\
\hline
\end{tabular}


جدول (Y)-ب: تأثير LAS على إزالة العناصر المعدنية في محطة التصفية .

\begin{tabular}{|c|c|c|c|c|c|}
\hline \multicolumn{5}{|c|}{ نسبة إزالة العناصر الفلزية \% } & \multirow{2}{*}{ محطة التصفية } \\
\hline $\mathbf{C u}$ & $\mathrm{Cr}$ & $\mathbf{P b}$ & Mn & $\mathbf{F e}$ & \\
\hline$\% \curlyvee \wedge$ & $\% \vee r$ & $\% 0$. & $\% \vee \diamond$ & $\% \wedge 0$ & معدة الماء الموحيز LAS في الماء الخام \\
\hline$\%$ \% & $\% \circ V$ & $\%$ ro & $\% \leqslant 0$ & $\%$ \% & محطة الاندان معل تركيز LAS في الماء الخام \\
\hline
\end{tabular}

ع - ب تعيين فعالية الكاريون المنشط بطريقة قياس الرقم اليودي :

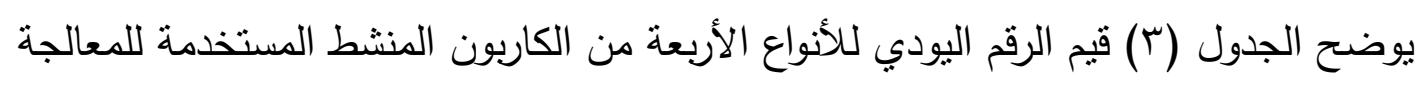

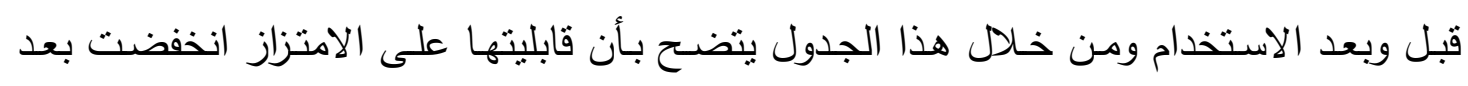

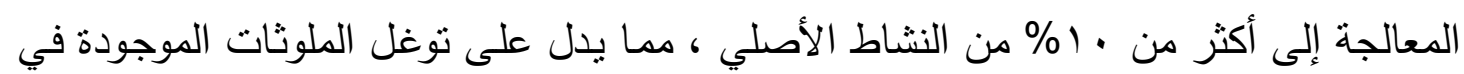

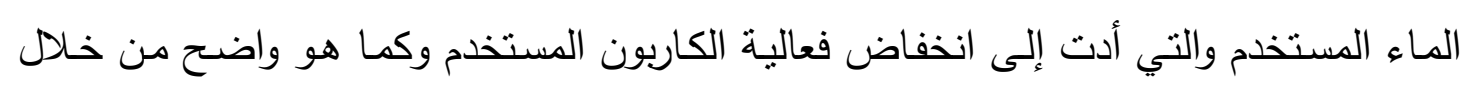

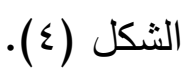

جدول رقم (ץ) : الرقم اليودي للكاريون المنشط قبل ويعد المعالجة

\begin{tabular}{|c|c|c|}
\hline الرقم اليودي بعد & الرقم اليودي قبل & نوع الكاريون المنشط \\
\hline 153.3 & 1313 & مولاس بالكبريتيك \\
\hline 110.5 & 965 & إسفلت بالكبريتيك \\
\hline 167.2 & 1379 & مولاس بالفسفوريك \\
\hline 150 & 1103 & إسفلت بالفسفوريك \\
\hline
\end{tabular}




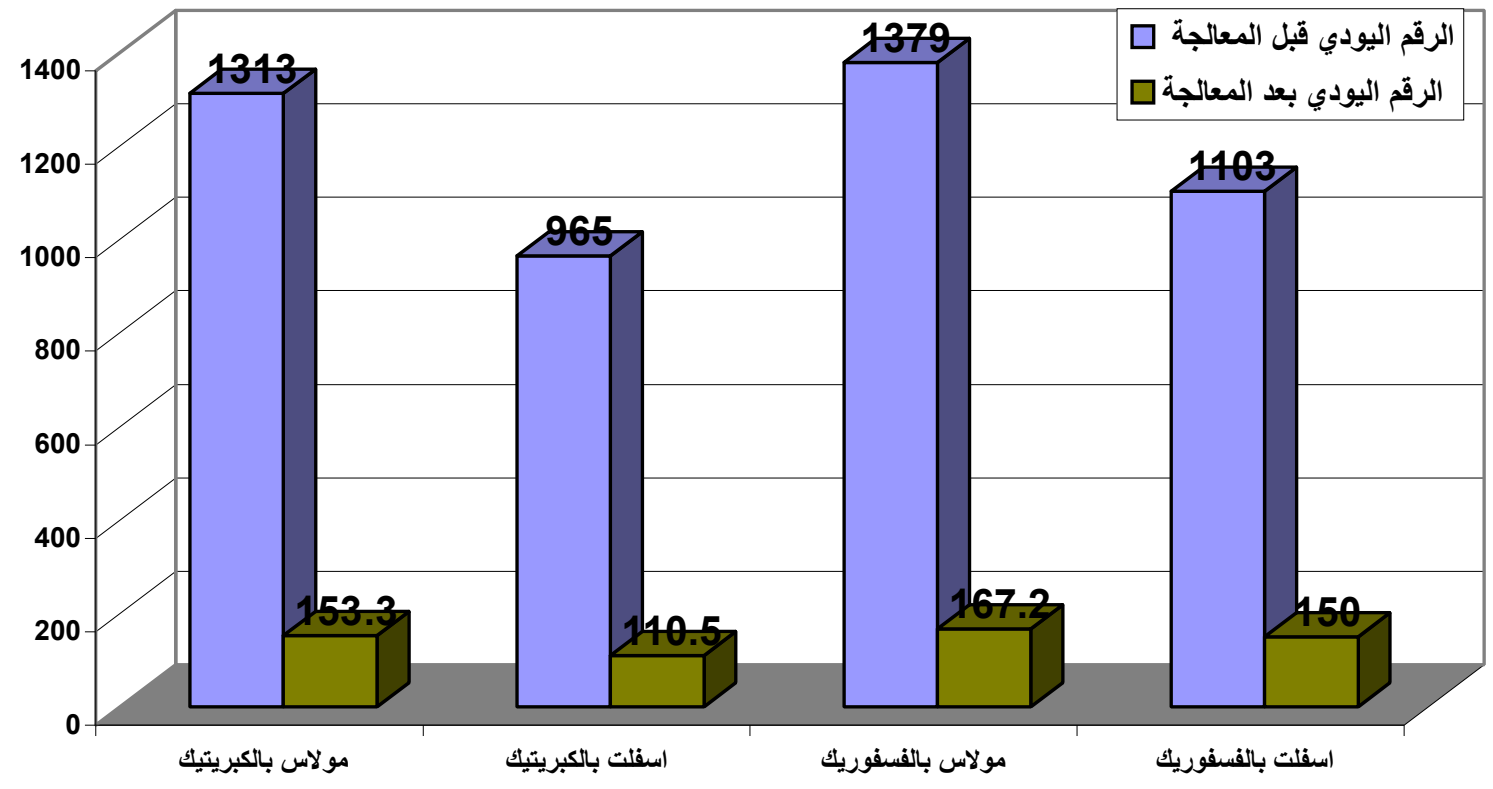

الثكل رقم (ع) : الرقم اليودي للكاريون المنثط قبل ويعد المعالجة .

3-5 تركيز جزيئات LAS قبل ويعد المعالجة باستخدام الكاريون المنشط

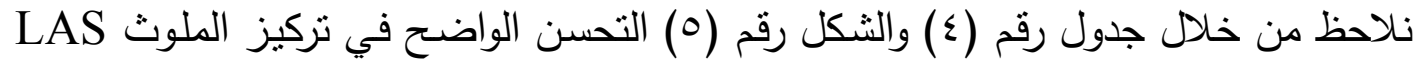

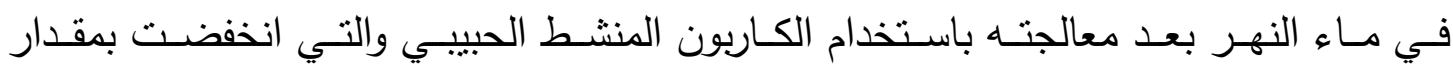

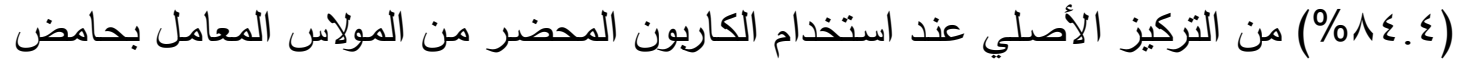

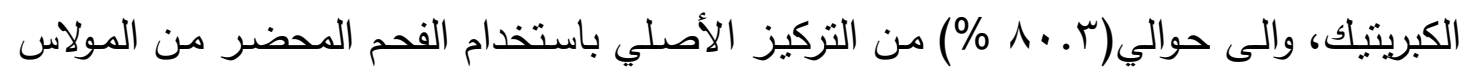

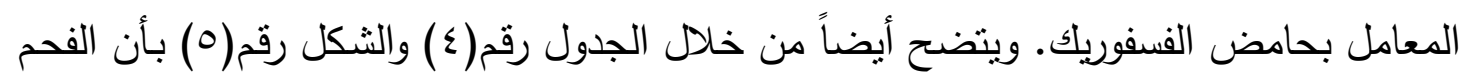

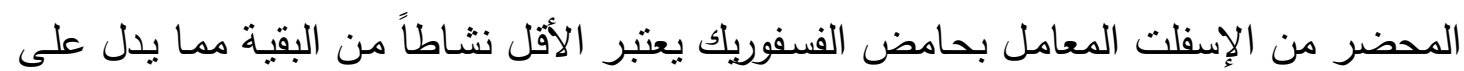
أن هذا النوع من الفحم قد بمنلك ثغور بحجم اصغر من حجم جزيئات LAS الكبيرة.

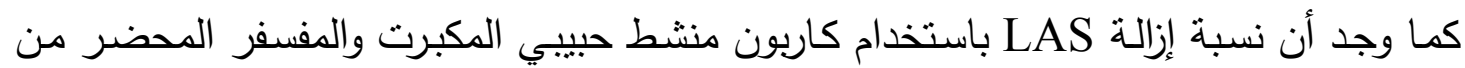

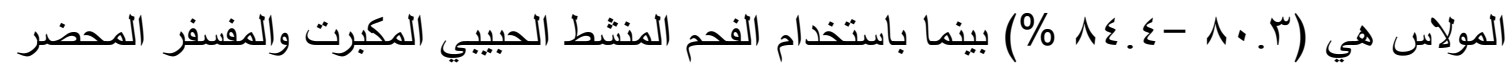

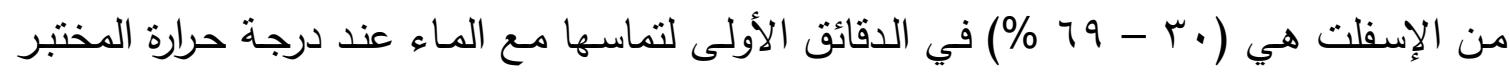

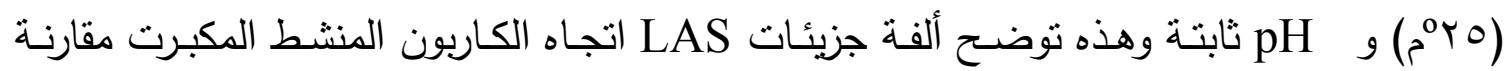

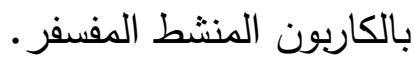


جدول رقم (؛) : تركيز LAS قبل ويعد المعالجة

\begin{tabular}{|c|c|c|}
\hline $\begin{array}{c}\text { CAS } \\
\text { بعد التنقية }\end{array}$ & تركيز & نوع الكاريون المنشط \\
\hline 0.05 & 0.32 & مولاس بالكبريتيك \\
\hline 0.1 & 0.32 & إسفلت بالكبريتيك \\
\hline 0.063 & 0.32 & مولاس بالفسفوريك \\
\hline 0.225 & 0.32 & إسفلت بالفسفوريك \\
\hline
\end{tabular}

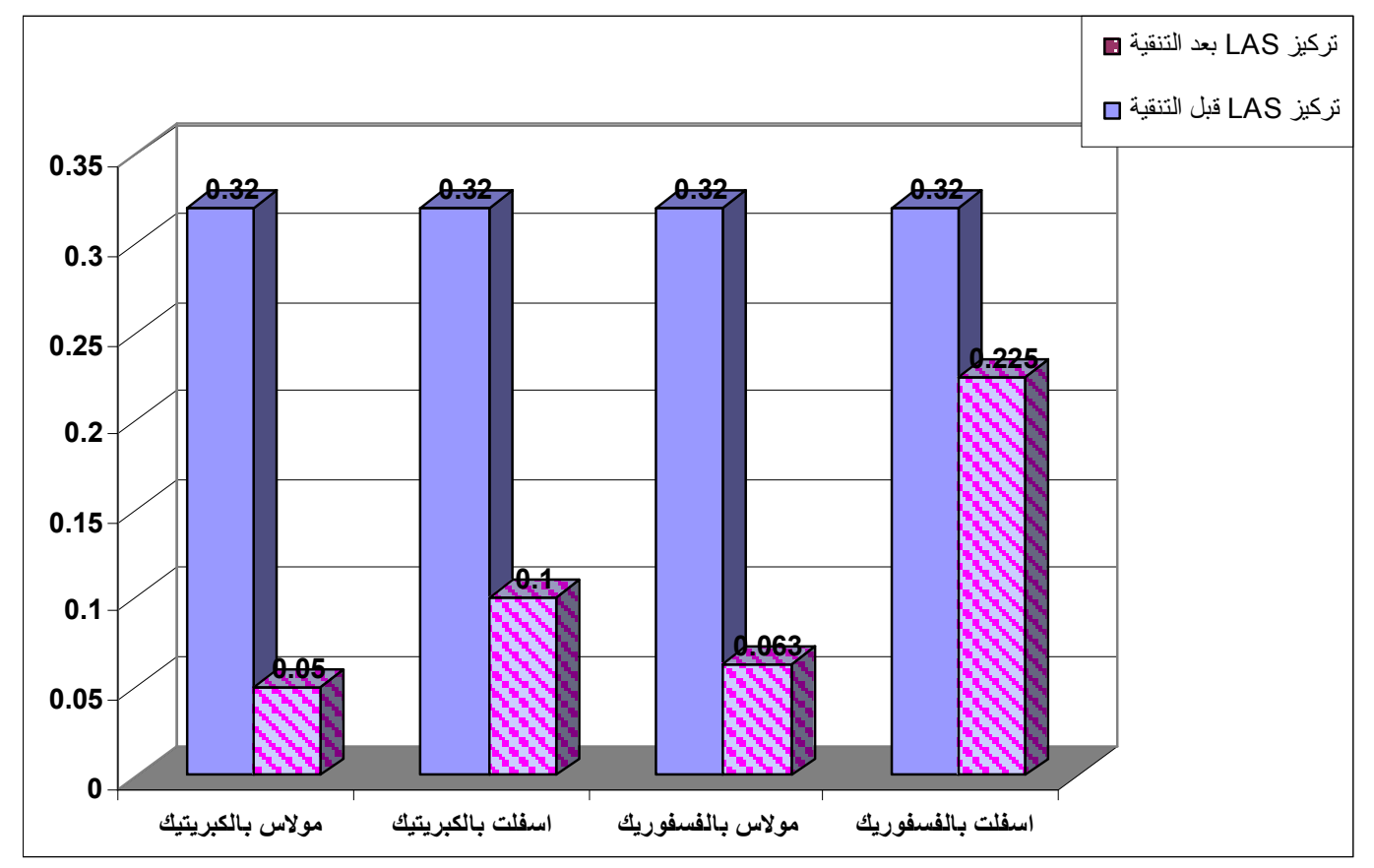

الثكل رقم (0) :تركيز جزيئات LAS

الاستنتاجات والتوصيات

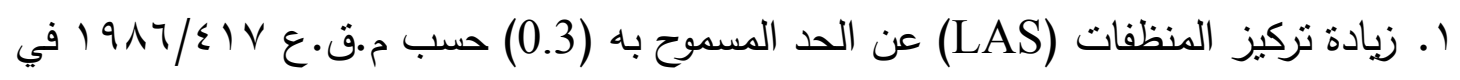

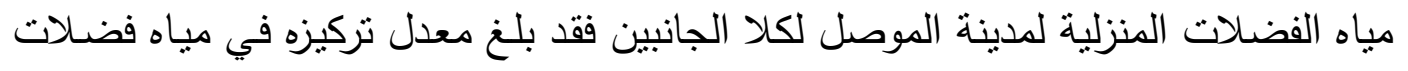

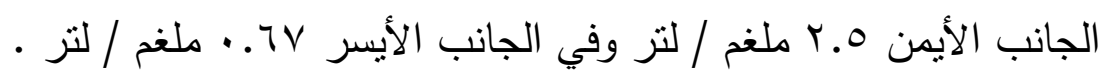
r. تجاوز نركيز المنظفات (LAS) النسب المسموح بها حسب الجبانب المواصفات القياسية في النهر

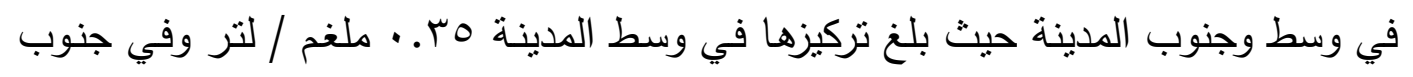

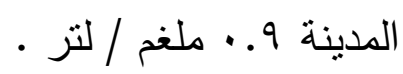


r. وجود مركب (LAS) في الماء الخام لمحطة التصفية يقلل من نسبة إزالة العناصر الفلزية التقيلة (Fe, Mn, Pb, Cr, Cu) في تلك المحطات حيث يعمل عامل انتشار لها مما لها

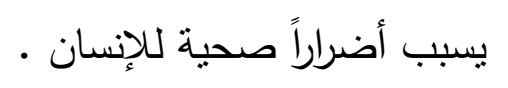

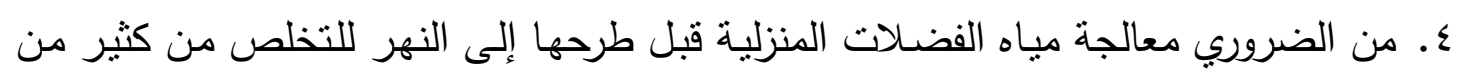

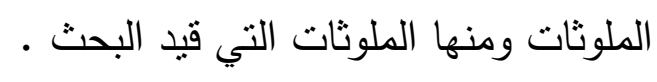

ه. تعتبر معالجة المباه الملوثة بمساحيق الغسيل بطريقة الامتزاز باستخدام الكاربون المنشط من

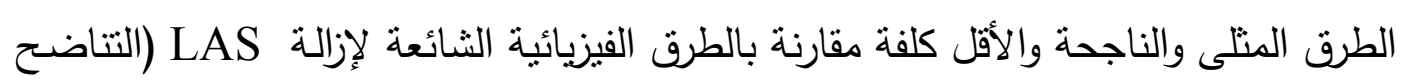

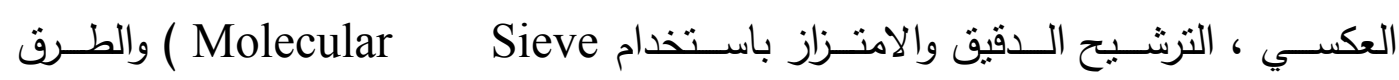

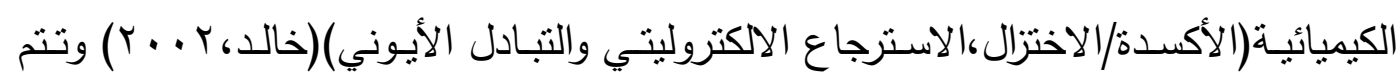

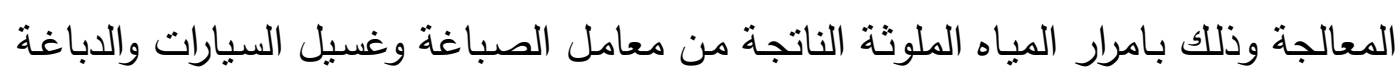

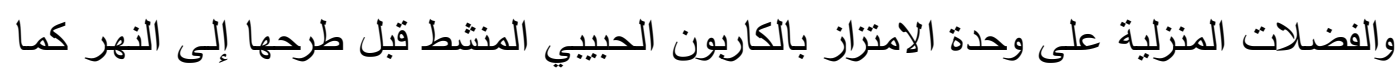

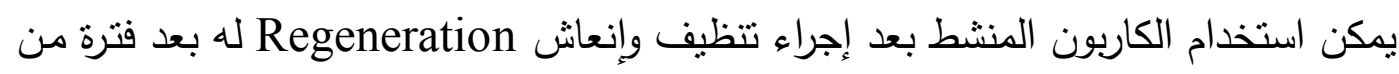
التشغيل لأنه يتشبع بالمواد الممتزة والعالقة.

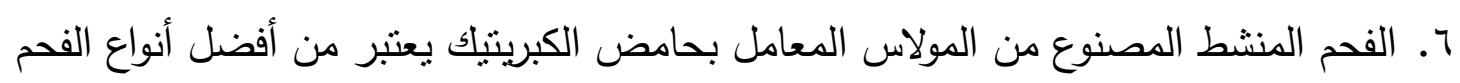
المستخدمة لمنل هذا الغرض وذلك للألفة الملاحظة لجزيئات LAS له.

\section{المصادر العربية}

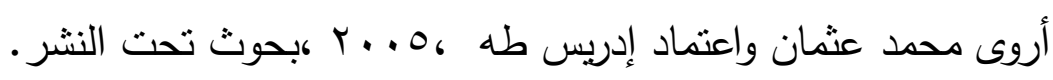

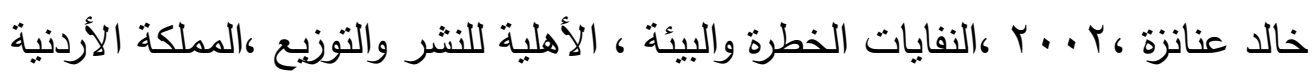

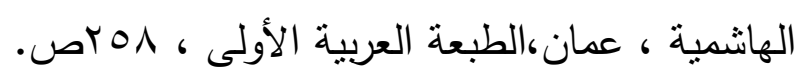

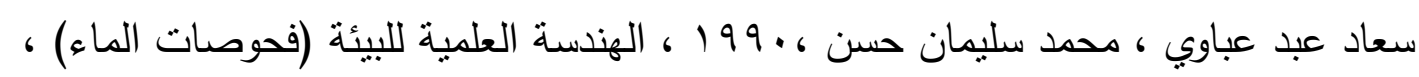

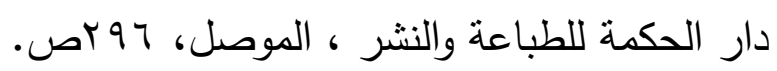

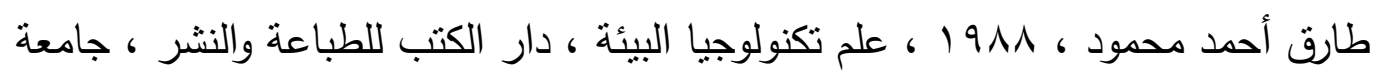

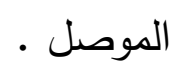

عماد وعد الله مهدي ، 1997 ، أطروحة دكتوراه ، تحضير كاربون منشط من نفط القيارة

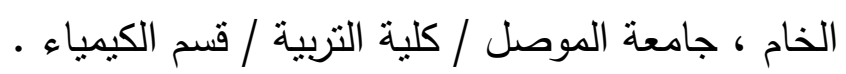




\section{المصادر الأجنبية}

Ali L. H. and Saleem F.F., 1988, Conversion of heavy crud oil vacuum bottoms to activated carbon, J. Petrol Res., Vol. 7, No. 2, pp. 22-49.

Annual Book of ASTM Standards:Standard Test Methods for Alkyl Benzene Sulfonate in Water:D2330-1982, part31,Water pp. 613-618. APHA, WPCF and AWWA: Standard Method for Examination of water and wastewater $14^{\text {th }}$. Ed., 1975.

Bruce W., 1969, Practical consideration in the Surfactant Aide Mobilization of Contamination in Aquifers, Jour, WPCF, Vol. 61, No.7.pp.

Carol H. T. and Rhodes R. T., 1977, Developing Drinking Water Standard, Jour. AWWA.

Floyd B. T., 1971 Trace Element and compound in waters,Vol.63, No.11.

Gardiner J., 1976, Complexation of Trace Metals by Ethylenediamine Tetra acetic Acid (EDTA) in Natural Waters, Water Research, Vol. 10, pp. 507-514.

Jim Economy, 2002, Department of Materials Science \& Engineering, Vol. 3, No. 7.

Michael H. 1988. A review of behavior and utilization of Polycarboxylic acid as detergents Builders, Environmental technology letters, Vol. 9, pp. 1-22.

Mohammed S. A., 1986. Pollution of water sources, chemical study on the pollution of Al-Khouser River, M. Sc. Thesis, Mosul University.

Nalewajko C., 1994. Effect of surfactants on Algae, Ergebmsse Der Limnologie, Vol. 2, P. 195.

Russell D., 1992, Extension associate in water, WWW. ext. nodak. edu / extpubs / h20qual watssys / ae - 1029,Feb.1992.

Saad M. El-Said, 2003, WWW. eeaa. gov. eg / English / Main /Env 2003/ Day2/ water / Saad.nwri.pdf.

Saleem F. F.,1978.Activated carbon preparation from heavycrude oil resudues, M. Sc. Thesis, Mosul University, P. 20-22.

William K., 1969, Effect of Colored Organics on Iron Removal AWWA, Vol. 61, No. 11.

WWW.edu.city.kyoto.JP/hp/murasaki/1999 htm. 